\title{
The acquisition of the high-tech enterprise strategic transformation
}

\author{
Lijie Song1, a \\ ${ }^{1}$ Capital University of Economics and Business, China \\ asonglijie_123@163.com
}

Keywords: strategic transformation. the high-tech enterprise. Baidu.

\begin{abstract}
With the development of science and technology, without a doubt, the development of mobile Internet brings more opportunities for high-tech enterprises. Many enterprises already have a larger scale of operation and impressive sales performance and have formed the core competitiveness of enterprises. How to permeate its own core competitive ability to the mobile Internet market and how to form their own Internet Ecosystem will be a huge challenge for the high-tech enterprises. In the methods of strategic transformation in high-tech enterprises, whether is the acquisition strategy an effective way? This paper will study the single case to prove the acquisition strategy is an effective way in the strategic transformation.
\end{abstract}

\section{Research background}

With the development of science and technology, more and more mobile internet terminals come into the lives of consumers. The popularization of mobile Internet terminal makes consumer lifestyle more kind, more convenient and cheaper. Without a doubt, the development of mobile Internet brings more opportunities for high-tech enterprises. In the mobile Internet market, high-tech enterprises' investment has increased gradually, its participation increased gradually and at the same time high-tech enterprises face more intense competition. Thus, the mobile Internet market in the future will be an important battlefield of high-tech enterprises competing for market share. With the maturity of mobile Internet, high-tech enterprises are accounted for the mobile Internet market share, which will affect the competitive ability of high-tech enterprises in the future. How much share the high-tech enterprises have in the mobile Internet market is decided by the market recognition of the enterprise products, however, the approval degree of products is affected by high-tech mobile's market strategy.

In the Internet market, a large number of high-tech enterprises are experiencing a critical period from growth to maturity. Many enterprises already have a larger scale of operation and impressive sales performance, and have formed the core competitiveness of enterprises. Under the background of mature Internet market and the rapid development of Internet, a large number of high-tech enterprises inevitably change the strategic direction to improve the mobile Internet market share. How to permeate its own core competitive ability to the mobile Internet market and how to form their own Internet Ecosystem will be a huge challenge for the high-tech enterprises. Under the background of the high speed development of mobile Internet, a large number of high-tech enterprises are in the key period of strategic transition, which means they are facing many significant issues, such as, how to choose the way of strategic transformation and how the internet ecosystem established will determine whether the healthy development of high-tech enterprises in the future.

The acquisition is one way of the enterprise's strategic transformation. The acquisition of the implementation in high-tech enterprises is not acting out of short-term interests of the enterprises, but planning for the long-term development of the enterprises. High-tech enterprises in the strategic transformation can quickly enter the mobile Internet market, fast access the industry barriers through the acquisition. The acquisition of an enterprise can provide a large amount of resources of acquired company to acquiring company. Through the ways of the integration of resources, permeability of core technology and rapid occupation of the market enhance the purchasing enterprises competitive advantage in the target. When the high-tech enterprises are in the selection of the acquisition target enterprise, an important selection point is that the value of the target 
enterprise is undervalued by the market. One important reason for the value of the target enterprise undervalued is that synergy value acquired enterprises bringing to the acquisition of the business does not show through market. After the acquisition of enterprises integrated its own core technology and the acquired business competitive advantage, the potential value of the acquired enterprises will be affirmed fully by the market through the value of coordination. Collaborative value is the difference between the price of the acquired enterprise and the market value of the acquired enterprise.

After the completion of the acquisition target of high-tech enterprises, high-tech enterprises integrate with the target enterprise. The integration of the target enterprise can go through the core integration, market integration, personnel integration, corporate culture integration and so on. In the integration of high-tech enterprises, the most attention is the core competitiveness. After the high-tech enterprises buy new enterprises, in integrating phase they will focus on how the enterprise's core technology is applied to the acquired business products and how to best increase the potential market value of acquired enterprises. After integration, high-tech enterprises will get new product competitive advantage to enhance the enterprise's core competitive ability. At this point the high-tech enterprises develop new products supporting the core technology. Advanced technology and excellent performance are the conditions to ensure the market share of new products. But they have much difference between the acquired enterprises and the acquisition enterprises like market share, the target customer and marketing methods. In order to ensure a high market share, companies need to integrate different target market and establish a perfect marketing strategy. In the process of integration, we will also merge two enterprise employees. Therefore, the acquiring enterprises should research the acquired enterprises' salary system and the training mechanism and train the acquired enterprises employees to increase their sense of corporate identity and loyalty, to reduce their sense of rejection and negative feeling, which ensures the integrity of the team and plays a synergistic effect. Enterprises will eventually integrate the corporate culture. The corporate culture is the key part of the enterprise. Culture influences all aspects of high-tech enterprises.

In the methods of strategic transformation in high-tech enterprises, whether is the acquisition strategy an effective way? This paper will study the single case to prove the acquisition strategy is an effective way in the strategic transformation. After the full analysis, we can obtain the answers about when the best time is to implement the acquisition and what the selection criteria is during the strategic transition. What should do after the completion of the acquisition? This is also the key point to this paper how integrate high-tech enterprises and target enterprises.

\section{Literature References}

In today's China, Internet behemoths, represented by BAT, have found themselves in a situation of tripartite confrontation in the Internet market, and, also they speed up the layout in mobile Internet market. Meanwhile, the emergence and rising of hundreds and thousands of other Internet companies have been making their own contribution to the development of Internet in China. Mergers and acquisitions are inevitable in such a competitive market. However, in terms of the following questions, namely, for enterprises, how and at what time to make an acquisition, what is the benefit of acquisitions, and whether they can seize opportunities in acquisitions, most companies cannot give a reasonable answer. In the article "Shanda Shakedown” (Liang Chen 2014) it points out that, Shanda Interactive Entertainment first accumulated its possessions as online game operator and developer, and pushed Shanda Game to go public. As Chen Tianqiao became one of the richest China's people, Shanda Interactive Entertainment made a deal acquiring video website Ku6.com. Whereas, instead of capturing video market, it was marginalized because of the rising and rapid growing of China's major Internet video portals, such as Sohu.com and Tudou.com, and soon afterwards,the shares of Ku6 was transferredaway from Shanda as a burden. In "Why is Balance Treasure”, Zhong Xiaolin says that, before Balance Treasure was invented, customers' balance in Alipaycannot get any benefits. Furthermore, due to the immaturity of China's interest rate liberalization, customers had few investment channels. After Alibaba acquired Tianhong Asset Management Co, customers' balance in their Alipay account was deposited into Tianhong Funds. In 
this way, users' balance of money in Alipay can get benefits. Alibaba acquired Tianhong Asset Management Cowith clear purpose. The combination of funds with Alipay products makes the best use of Tianhong Funds. In many acquisition cases for foreign companies, the main challenges faced by enterprises are how to grasp opportunities and integrate after series purchasing. In "Paypal: Online Payment Hegemony" (Lei Baozhong 2006), it indicates that Paypal was the 3rd largest Internet payment company back then. About $10 \%$ users of eBay were using Paypal at first, and the figure dramatically increased to 62\% when eBay had intent to acquire Paypal. After the acquisition, eBay successfully integrated Paypal along with its own advantages, which had been making a synergistic effect ever since.

In "Research of the Acquisition and Restructuring Strategy" (Li Jing 2005), it denotes that the acquisition is the primary method of the development of enterprises, and successful acquisition integration of an acquired company is a major undertaking. In "How does the Match of Acquiring Firms and Target Firms Affect their Performance” (Li Shanmin 2004), some exploring studies had been done to find the characteristic of the match between the acquiring companies and the target companies which improves both their performance. In "Does the Market Expectation Performance of Listed Chinese Companies Achieved” (Di Jinbu 2010), it analyzes the performance implication for the largest $191 \mathrm{M} \& A s$ of listed Chinese companies. The author not only uses event study methodology to analyze the market expectation of performance improvement from M\&A, also, from the point view of the cash earning, which can be hard to manipulate, it uses financial index sign to analyze the financial performance from M\&A. The above paper has a practical significance to this paper in terms of the measurement of market expectation performance from M\&A.

\section{Case study illustrates Baidu takeover 91 assistant}

\section{Robin Li, the CEO of Baidu, has boycotted mobile Internet}

When Baidu was founded, the number of netizen is 9 million and search engines were Baidu's critical technique. Robin $\mathrm{Li}$ had not understood how the mobile Internet works until 2009. He simply thought mobile search and web search were the same, except that mobile search works on small screen with lower speed. Li ignored the advice, which was transferring from web search to mobile Internet, instead, he simply spent more time and expenditure on web search field. In 2009, Iphone accessed to the Chinese market and Andriod became popular. Smartphone and tablet device became requisite in people's daily life.

With the development of high-speed Smartphone, a lot of public places in China have been covered with free WIFI, such as airport, railway station, bus station and commercial hub. The number of free WIFI users has been sharply increasing, as well as the using frequency. Free WIFI brings enormous business opportunities and commercial value, which is one of the prerequisites of major Internet companies' strategy layout. Smartphone and table device change people's lifestyle, at the same time promote the development of the technology of mobile Internet. As a carrier of mobile Internet, Smartphone and table device become a main route for Internet companies entering into mobile Internet market.

After in-depth analysis, Robin Li realized the great difference between mobile search and web search. Mobile search users prefer to find answers quickly. Robin Li said when Smartphone users use mobile to search, they did not wish to take McDonald's official website display first but to tell them how to get to the nearest McDonald's. Robin Li completely did not foresee such consumer's expectations, hence Baidu was forced to do a lot of work to make up the gap.

\section{The reason of Baidu taking over 91 Assistant}

Baidu, the leader in the Internet industry, generated the largest amount of network traffic flow in China. However, with the rapid development of mobile Internet, her advantage gradually tapered off. Due to missing the best opportunities to develop mobile Internet, the strategy formulation and the way of transform strategy are particularly important.

In the mobile Internet market, Baidu adopts the strategy named "cloud \&port”, which means wireless search and app store. In the field of wireless search, Baidu has accumulated a great deal of 
experience. In the field of app store, although Baidu established her own store in the mobile Internet market, it does not work well. Thus, there is not sufficient preponderance of her new strategy which cannot support the development of Baidu. If Baidu'd like to keep her preeminence, she must snatch time, seize opportunities and produce the capital advantage to acquire target enterprises in order to get more entrance and channel in the mobile Internet market.

After plentiful research, Baidu locks its target, 91 Wireless Firm. 91 Wireless Firm includes 91 Mobile Phone, Mobile Phone Portal, 91 Panda Reading and Android products and so on. 91 Wireless, which completely supports systems of iPhone, iPad and Android, is a mobile phone management PC tool. 91 Wireless set a platform for Smartphone' application, which has occupied domestic leading level. To gain competitive advantage and implement the strategy, cloud \& port, 91 Wireless is a wise choice for Baidu.

Acquiring 91 Wireless was not the only aim. After acquiring 91 Wireless, Baidu could form an eco-system including supplying, producing and selling. Eco-system included both the Internet and the mobile Internet. In the Internet field, Baidu integrated Baidu Post Bar, Baidu encyclopedia and Baidu Library into searching engine to form an information platform. In the mobile Internet field, Baidu integrated Cloud and Port to form a mobile information platform. Of course, the development of mobile Internet needed a lot of developers, consumers and suppliers.

However, Tencent and Alibaba, Baidu's competitors, promote their own products in the mobile Internet market. Tencent products such as WeChat, QQ and QQ mobile Game have been assured of a place in mobile Internet market. Alibaba designed mobile phone software such as TaoBao and Tmall. To form eco-system, Alibaba held the share of Weibo and High German map. Because competitors built their own eco-system, Baidu has confidence and resolution to build her eco-system.

\section{The process of acquiring 91 Assistant}

Before Baidu acquired 91 Wireless, 91 Wireless got ready to go public in HK. 91 Wireless had introduced a powerful strategic investor-Richard Lee, who invested 17.8 million to 91 Wireless with other investors. The valuation of 91 Wireless was 22 billons yuan at that time. 91 Wireless could remedy Baidu's weaknesses in mobile Internet market. After acquiring 91 Wireless, Baidu, improved its market share, increased its entrance, strengthened cash ability and built Internet eco-system. Thus, it seems that, 91 Wireless brings higher strategic valuation than market valuation. Of course, there are many potential buyers, for example Alibaba, another Internet giant, trying to make 91 Wireless its own. Alibaba revealed an intention to buy 91 Wireless, which led to a higher purchase price for Baidu. Base on the market valuations and the strategic value, considering competition from other companies, Baidu took full control of 91 Wireless Firm with a price of \$1.9 billion. Baidu bought a stake of $57.41 \%$ from 91 Wireless' parent company, The Dragon, and 42.59\% from other shareholders.

\section{The integration after the acquisition}

(1) Consolidate core competence

The core competence of Baidu is search engine. While the core competence of 91 Wireless is application development and game development, the market share of Baidu Assistant, an application Baidu developed by her own staff, is lower than 91 Wireless Firms. Baidu integrated two different core competences together, as well as two different applications. When mobile phone users search a mobile app or game using Baidu mobile searching engine, the download link of that app er game in Badiu Assistant would show up. The users can download what they want by clicking the corresponding links.

(2) Integrate marketing

In the developer market, the interaction, relationship between 91 Wireless and developers, and the distribution demands of developers had formed a perfect system before the acquisition. 91 Wireless understood well of the demands of small, medium and large group of developers, and was proficient in the promotion of those first published applications and the liquidity of the products. In traditional Internet, relying on webmasters Baidu finally rose up. After acquiring 91 Wireless, the 
mobile alliance of the system of 91Wireless, Baidu' mobile security system and payment platform was formed.

In the consumer market, in terms of market acceptance, 91 Assistant which concentrated on the development and expansion of Internet products had a higher reputation than Baidu Assistant. The number of 91 Assistant users reached 127 million by the end of Sep 2012 and the overall application downloads of 91 Assistant and Android App store was over ten billion. Baidu Assistant and 91 Assistant were of high similarity. Therefore, acquisition strategy increased consumer groups for Baidu.

(3) Culture integration

91 Wireless Firm had the strong execution and the problem solving capabilities. Baidu, as an Internet giant, has a standard company structure and the coordination of different departments plays a significant role in its business operation. If Baidu's managers wanted to keep the flexibility of the team of 91 Wireless, they should create a leisurely and carefree working atmosphere of to produce the synergistic effect.

(4) Human resource integration

Considering the advantage of the employers and technology of 91 Wireless, Baidu formulated a rule that the employers of 91 Wireless had to work for 2 years in Baidu. After two years, they can choose to stay or leave. The aim of this rule is to keep the integrity and sustainability of 91 Wireless. At the same time, Baidu's culture can permeate into the 91 Wireless Firm, finally the two companies will become one intact company.

\section{Conclusion}

The rapid development of mobile Internet market leads high-tech enterprises into a critical point. The acquisition strategy is an effective way in strategy transformation in the broader context. But the enterprises should use the rationality condition to fulfill acquisition strategies. First of all, the enterprises should be big enough and rich enough. Secondly, on the choice of acquired enterprises, they should remedy acquiring enterprises' neglects or bring synergism to improve acquiring enterprises' competitive ability. Finally, the acquiring enterprises should find a suitable way to integrate two enterprises.

With the rapid development of the Internet, the internet giants, BAT, are creating their own eco-system in the field of Internet. IT FIN and mobile internet will bring a lot of opportunities and challenges. High-tech enterprises must use the innovative business models and innovative marketing strategy to achieve success.

\section{References}

[1] Liang Chen. “Shanda Shakedown,” Capital Market, Sep 10, (2014) pp.75-77.

[2] Lei Baozhong. “Paypal: Online Payment Hegemony,” PROPERTY RIGHTS GUIDE. (2006) pp.50-51.

[3] Li Jing. "Research of the Acquisition and Restructuring Strategy," POLICY RESEARCH \& EXPLORATION (2005)

[4] Li Shanmin. "How does the Match of Acquiring Firms and Target Firms Affect their Performance,” Economic Research Journal (2004) pp.96-104.

[5] Di Jinbu. "Does the Market Expectation Performance of Listed Chinese Companies Achieved," Journal of Financial Research. (2010) pp.133-151. 